\title{
Intelligent System for Smart Cultivation - to Integrate Technology in Rural Economic Development
}

\author{
B V A N S S Prabhakar Rao, Kadupukotla Satish Kumar, P Rabindra Kumar Singh, P Sundeep
}

\begin{abstract}
Since all living organisms require food and farming is the best key division of any country's economy development. In many developing countries the price of agriculture commodity is very low due to many issues. From a billionaire who has bread and jam for breakfast to the poor who eats rice porridge everyone who needs food for living on this earth has a relation to agriculture. The farmer, even if he is or isn't profited for years together with the crop that he has sown he keeps searching for his life in every seed he sows in hope of succeeding. Hence, along with the price hikes in the market, adulteration is also on the rise, if this continues similarly, the wealth you'd give your children in the future won't be enough even for their hospital expenses. Price of land is growing day by day and the value of farmer is coming down, if we start constructing everything on this land then there would be no place for cultivating food. This work is based on gaining good returns for farmers by farmers meeting their own customers, but no relation to dealers this helps in farmers getting their price for the work they do. This helps in good food without adulterant products that leads in good health, hence good business returns in good benefits of returns to the economic growth of the country. Major contribution is required to implement minimum support price. Lots of researchers reported the need of MSPs but no implementation strategies so far in many products. The main focus of this work is to provide food for our growing population; we need to adopt certain agricultural practices with the help of technology in terms of machine intelligence with smart cultivation for crop production and management.
\end{abstract}

Keywords: Crop, Fertilizer, Harvesting, Insurance, Intelligent, Irrigation, Kharif, MSP, Plough, Rabi, Smart, Sowing, \& Weeds.

\section{INTRODUCTION}

India is the world's largest producer of pulses, rice, wheat, spices and spice products. As per the recent report Indian agriculture sector accounts for eighteen per cent of GDP and provides direct or indirect employment to fifty percent of India's labor force [1\& 9].

Revised Manuscript Received on February 05, 2020.

* Correspondence Author

Dr. B V A N S S Prabhakar Rao*, School of Computing Science \& Engineering Vellore Institute of Technology, Chennai

Dr. Kadupukotla Satish Kumar, Dept. of CSE, St.Peters Engineering College, Hyderabad.

P RABINDRA KUMAR SINGH, School of Computing Science \& Engineering Vellore Institute of Technology, Chennai

P SUNDEEP, School of Computing Science \& Engineering Vellore Institute of Technology, Chennai

(C) The Authors. Published by Blue Eyes Intelligence Engineering and Sciences Publication (BEIESP). This is an open access article under the CC BY-NC-ND license (http://creativecommons.org/licenses/by-nc-nd/4.0/)

\section{Hard Worker - Why Poor?}

The farmers of many countries are the hardest worker, farmer from all over the world. They are being always busy in the farming for the crops by working day and night. They use to plough the land and in that they sow the seeds for the growth of the crops [6].

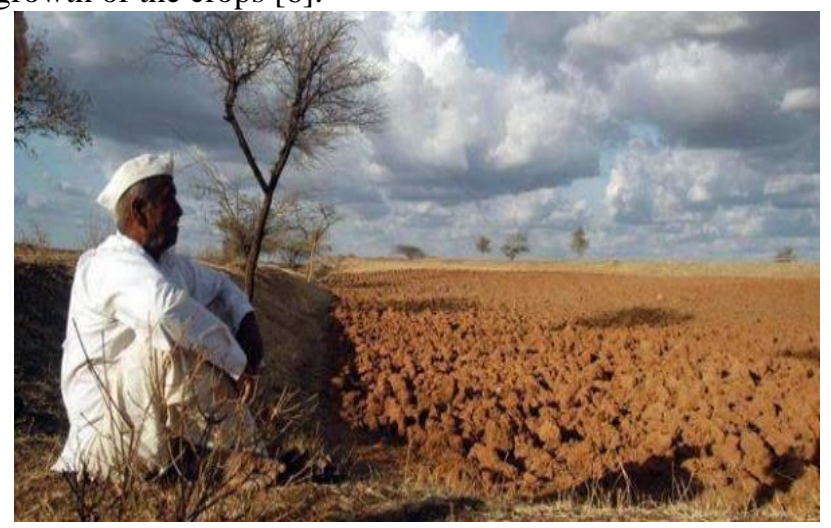

Fig. 1 Hope - Farmer Waiting for ....

Research Objective:

As per the fig. 1 all most all the farmers are waiting for support in many ways right from human being to god almighty including may insects, trees, sun, etc.. They are the real backbones for the society in many forms. But, their returns are almost peanuts. We can't imagine our life without their support and encouragement. This research work mainly focused on farmers. Since directly or indirectly, without our knowledge, agriculture is one of the significant areas of national economy [2-5]. In many zones the price of agriculture commodity is very low due to some issues. In spite of their life style their direct contribution to the society is as follows:

1. Contribution to National Income

2. Source of Food Supply

3. Prerequisite for Raw Material

4. Provision of Surplus

5. Shift of Manpower

6. Creation of Infrastructure

7. Relief from Shortage of Capital

8. Helpful to Reduce Inequality

9. Based on Democratic Notions

10. Create Effective Demand

11. Helpful in Phasing out Economic Depression

12. Trade Revenue with respect to Foreign Exchange

13. Agriculture Capital Formation in different ways

14. Employment Opportunities for Rural People

15. Agriculture plays vital role in the Indian economy.

16. Health via unlimited wealth

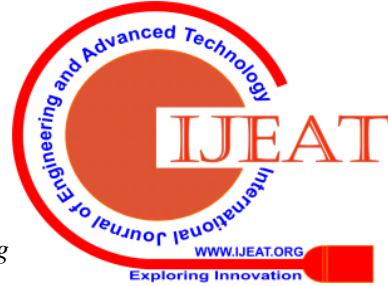




\section{PROCEDURE FOR CULTIVATION}

Now a day everyone speaks about the need for organic product development without the usage of fertilizers to save lives. The following practices have been monitored to cultivate land to produce rice, wheat and other food crops in traditional agricultural:

- Preparation of Soil

- Sowing

- Adding manure and fertilizers

- Irrigation

- Protecting from weeds

- Harvesting

- Storage

In general, if you see the above stage of cultivation it is very simple and we may feel that entirely easy process. But to get crop out how the farmers are struggling their life we may not know the actual difficulties. When we see the nature or the process or preparation of food grains in a movie or song or pic are always so beautiful like ice-berg tip. Fig. 2 clearly shows the imaginary process of cultivation most of us may visualize without knowing the ground reality in detail [7 \& 8].

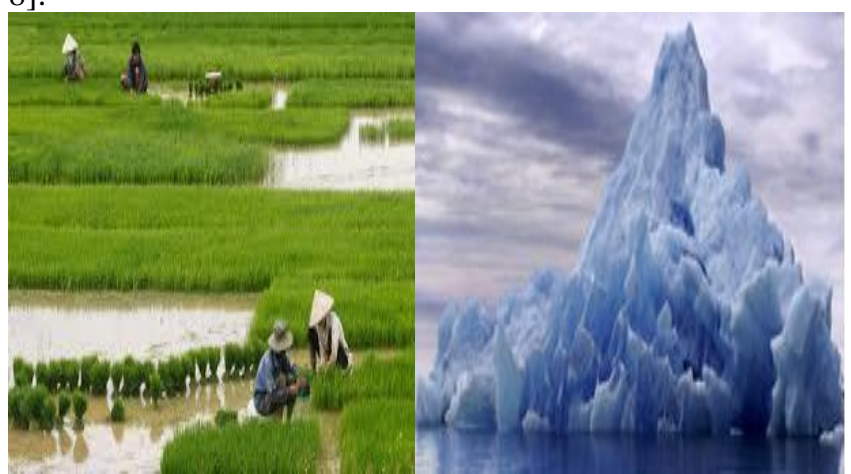

Fig. 2 Cultivation - Ice-berg Process

\section{Why Farmer Suicide?}

Many studies suggested to Government authorities to prevent farmer suicide.

But, no use!

$$
\text { Why? }
$$

It's a million dollar question - Till date unsolvable!

Of course, these unfortunate incidents are not an isolated one in our country.

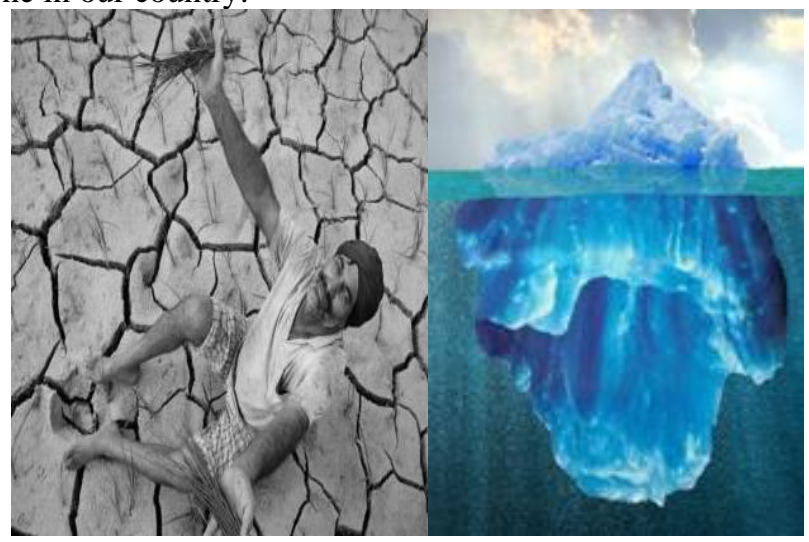

Fig. 3 No Hope Cultivation Process - Ice-berg Reality Fig. 3 shows one horrible situation based by the farmer clearly. Also shows that real farmers only face day to day process struggle with the ground reality. Hence, there is an urgent need to think for better intelligent system instead of

speaking too much on the issues faced by the farmers.

\section{SMART CULTIVATION PROCEDURE}

Cultivation has been used since ancient times for tilling the soil, adding fertilizers, removing the weeds, scraping of soil etc. For this purpose our ancestors used pair bulls, horses, camels, etc., based on their availability.

Smart Cultivation procedures discussed in detail with the help of the following steps:

\section{1: Preparation of Soil}

Prepare soil by tilling and leveling. Develop different modern tools for the purpose of ploughs and levelers.

\section{2: Sowing}

Seed drills, Use appropriate measures for Sowing of seeds at depths and distances provides better yield.

\section{3: Adding manure and fertilizers}

Soil needs replenishment and enrichment through the use of organic manure and fertilizers. Use of chemical fertilizers has increased tremendously with the introduction of new crop varieties.

\section{4: Irrigation - Modern Methods}

At appropriate intervals water supply of crops.

\section{5: Protecting from weeds}

Weeding involves removal of unwanted and uncultivated plants.

\section{6: Harvesting with Modern Machines}

Include scientific methods with respect to cutting of the mature crop by modern machines.

\section{7: Threshing}

Separation of the grains from the chaff

\section{8: Storage - Natural / Cold storage / FCI goo downs}

Proper storage of grains is necessary to protect them from pests and microorganisms

\section{9: Marketing - Fix Minimum Support Price (MSPs)}

With the help of technology the system need to suggest appropriate price for the product

\section{INTELLIGENT SYSTEM - SMART CULTIVATION}

Smart Cultivation with Machine Learning Approach:

To solve an issue with man-made machines we require a procedure, which should be approved out to convert the given source input in different formats to a machine readable one as output to complete the given task within the prescribed time frame. Machine Learning approach is not a new one but, train the computer system with the learning tradition just like a human how he/she trained and learned with the help of past 
experience and data to complete the given job with the optimized performance.

Many farmers know the procedure without depending on the machine. Hence our job is to inculcate the habit of self-learning the machine in order to take the decision in the cultivation process.

For example, after the rain, the farmer can easily identify the soil, whether it is fit for or not!
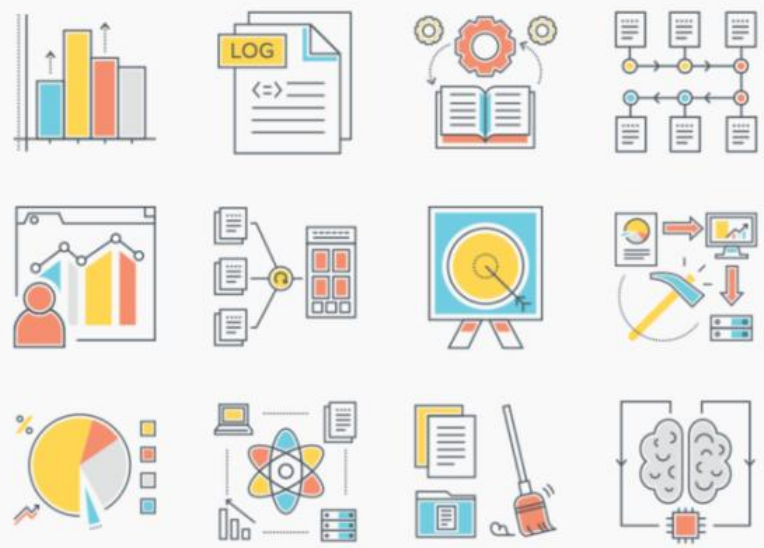

Fig. 5 Intelligent System with Machine Learning

Fig. 5 clearly show that different phases of Intelligent System design with Machine Learning such as

\section{- Problem Assessment}

\section{$>$ Specify the Objective}

Beneficiary fund transfer as per the need and season with respect to type of the crop
$>\mathrm{Sl}$ No
$>$ Beneficiary Name
$>\mathrm{C} / \mathrm{O}$ Name
$>$ Crop Name
$>$ Survey No or Lec No
$>$ Actual Cultivator
$>$ Area Damaged In Acre Above 33\%
$>$ Area Damaged In Acre Below 33\% Belonging to SF/MF Belonging other than SF/MF
$>$ Scale Of Relief(Rs Per Acre) $\mathrm{SF} / \mathrm{MF}$
$>$ No Of Farmers Effected SF/MF
$>$ No Of Farmers Effected OF
$>$ Total
$>$ Adangal
$>$ Bank Ifsc Code
$>$ Bank Account Number

$>$ Area Damaged Above 33\% In Acres Area

$>$ Area Damaged Above 33\% In Acres Area

$>$ Input Subsidy Required in Rupees SF/MF

$>$ Input Subsidy Required in Rupees Other than

- Data and Knowledge Acquisition

\section{> Analyze Data with available knowledge}

Table 1 provides sample data with respect to a village on a particular season available crop detail with acres or cents and if there is any damage what are level say for example 33\% above damage, etc. Since the insurance, bank people or any Government benefit schemes can be applied to that particular survey number and the system can process the fund or resource transfer to the beneficiary.

- Table- II: Data Processing for Training \& Learning

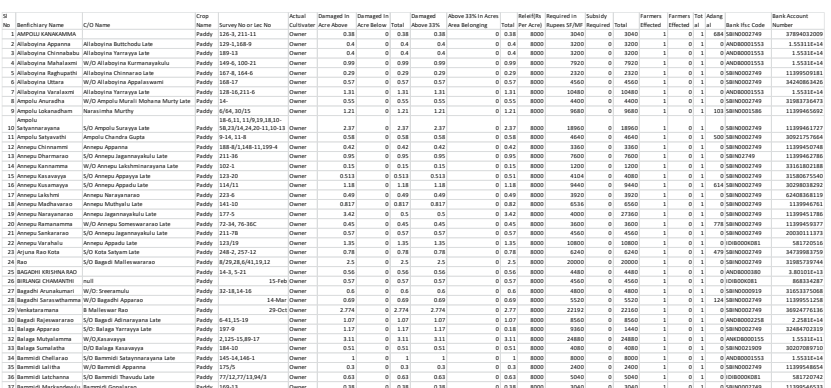

- Development of a Prototype System

$>$ Tool Identification with the situation

Table- III: Process Tool Identification with situation

\begin{tabular}{|c|c|c|c|}
\hline S.NO. VILAGE NAME & $\begin{array}{l}\text { DOCUMENTATION NUMBER } \\
\text { D }\end{array}$ & CITIZEN NAME & ACTION TAKEN SUBJECT \\
\hline 1 Akkayyavalasa & 2018-176862612193 & Tulugu Naravanarao & ACTION_TAKEN Teak trees damage \\
\hline 2 Cheepurlapadu & 2018-177027812263 & Chennamsetti Pentayya & ACTION_TAKEN Roof rakes flown away \\
\hline 3 Cheepurlapadu & 2018-177027661685 & Chennamsetti Rambabu & ACTION_TAKEN Trees fell down \\
\hline 4 Cheepurlapadu & 2018-177035014255 & Sadunapalli Adinarayana & ACTION_TAKEN Trees fell down \\
\hline 5 Cheepurlapadu & 2018-177032466668 & Sadunupalli Ramamurty & ACTION_TAKEN Trees fell down \\
\hline 6 Cheepurlapadu & $2018-177034556062$ & Sadunupalli Siva & ACTION_TAKEN Trees fell down \\
\hline 7 Cheepurlapadu & 2018-176913242606 & Sadunupalli Srinu & ACTION_TAKEN Roof rakes flown away \\
\hline 8 Chinavenkatapuram & 2018-1768177244460 & Boddepalli Raminaidu & ACTION_tAKEN Teak trees damage \\
\hline 9 Chittivalasa & 2018-177146011448 & Patta Kasipathi & ACTION_TAKEN HORTICULTURE CROP DAMAGE \\
\hline 10 Chittivalasa & $1100-17664467$ & Patta Kasipathi & ACTION TAKEN Water Scarcity \\
\hline 11 Chittivalasa & 2018-177 & Pattu Simhadri & ACTION_TAKEN Crop damaged \\
\hline 12 Chittivalasa & $2018-176819423360$ & Santha Rao Ampolu & ACTION_TAKEN Trees fell down \\
\hline 13 Chittivalasa & 2018-176824478138 & Santha Rao Ampolu & ACTION_TAKEN Teak trees damage \\
\hline 14 Chittivalasa & 2018-176827017257 & Santha Rao Ampolu & ACTION TAKEN Palm trees damage \\
\hline 15 Dantha & 2018-176873376026 & Goddu Kavitha & ACTION_TAKEN Roof rakes flown away \\
\hline 16 Dantha & $1100-17699662$ & VELAMALA ANARD DHANABAO & ACTION TAKEN Trees fell down \\
\hline 17 Duppalapadu & $2018-2018077525$ & Gollapalli Venkateswararao & ACTION_TAKEN C \\
\hline 18 Duppalapadu & $1100-17661009$ & Guruvelli Tirupathirao & ACTION_TAKEN ELECTRIC POLES FELL DOWN \\
\hline 19 Duppalapadu & 2018-177021519076 & Kuna Appanna & ACTION_TAKEN Teak trees damage \\
\hline 20 Duppalapadu & $1100-17664288$ & Mamidi Prasada Rao & ACTION_TAKEN ELECTRIC POLES FELL DOWN \\
\hline 21 Duppalapadu & 2018-176909343778 & Yenda Narisimha murthy & ACTION TAKEN Teak trees damage \\
\hline 22 Gangaram & 2018-1766888874738 & Korrai Chalapatirao & ACTION TAEEN \\
\hline & & ad & a \\
\hline 24 Gunililova & $2018-2018080238$ & Bendi Appayya & ACTION TAKEN Crop damaged \\
\hline
\end{tabular}

The System can take a decision on the given situation and appropriate action will takes place with a proper measure.

- Development of a Complete System

$>$ User Interface Design

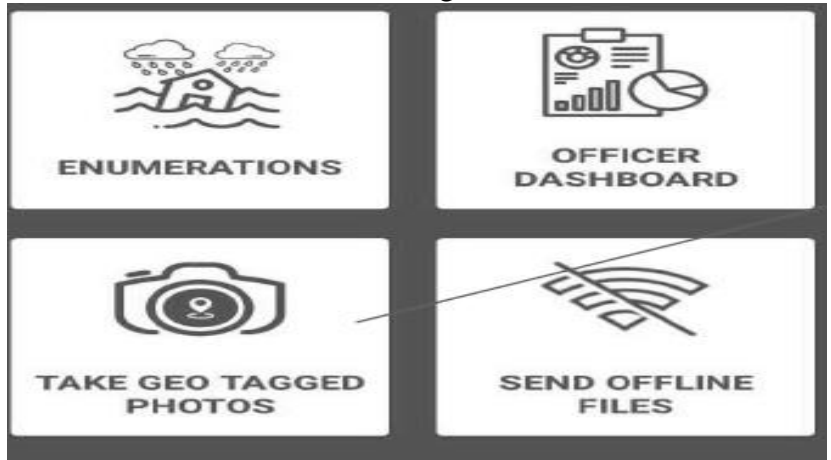

Fig. 6 Intelligent System for Data Collection UI

- Evaluation and Revision of the System

$>$ Revise as per Performance Criteria

Beneficiary

Name

B V A N S S

Actual

Cultivator

Prabhakara Rao

Crop Name

Owner

Paddy

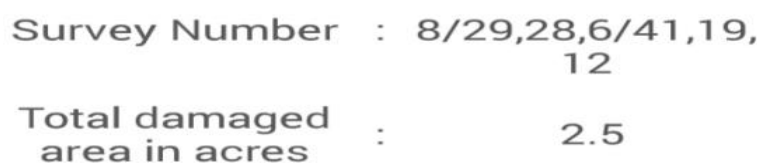

- Integration and Maintenance of the System

$>$ Technology to fix the problem 
As per the estimation, what amount of fertilizers required or what kind of remedial actions should be taken to bring the situation into our control.

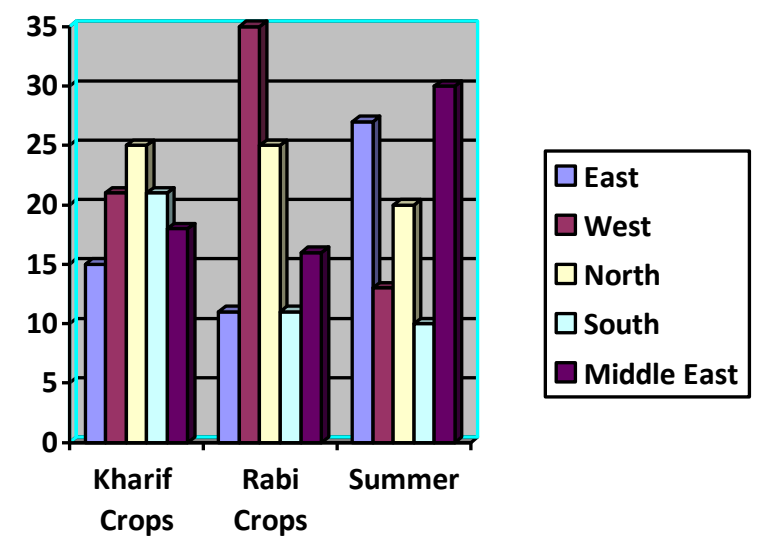

Fig. 7 Crop Production as per season

Hence, as shown in the fig. 7 different crops with various season how it develops an Advisory system for better yielding. Generally, these ML models need more data for processing to manage the situation than only training and learning can happen in a better way. For that reason we can collect the data from the revenue village as per the survey number and boundary of the village. India has the capacity to produce lots of foodstuffs. No doubt that can make a remarkable change in the country's economy. Also, the government wishes to offer support in case of crop insurance, farmer health card schemes to support their health and stop suicides, bank loans and other instruments for cultivation to the farmers' adoption of the technology that improves the economy.

\section{FUZZY LOGIC IN INTELLIGENT SYSTEM FOR BETTER RECOMMENDATIONS}

$\begin{array}{clll}\text { SNo } & \begin{array}{c}\text { Horticulture } \\ \text { Department }\end{array} & \begin{array}{c}\text { Total Area } \\ \text { Damaged }\end{array} & \begin{array}{c}\text { Damaged } \\ \text { (above } \\ 33 \%)\end{array} \\ 1 & \text { BANANA } & 2936.975 & 2630.32 \\ 2 & \text { Banana } & 41.8 & 49.25 \\ 3 & \text { COCONUT } & 2.6 & 2.6 \\ 4 & \text { COCONUT } & 1.83 & 1.83 \\ 5 & \text { Cashew } & 65208.77 & 61233.99 \\ 6 & \text { Coconut } & 42571.3 & 44663.37 \\ 7 & \text { MANGO } & 4.5 & 2.5 \\ 8 & \text { Mango } & 5666.254 & 5605.781 \\ 9 & \text { OILPALM } & 0.6 & 0.6 \\ 10 & \text { Oil Palm } & 77.29 & 76.94 \\ 11 & \text { Others } & 772.36 & 735.95 \\ 12 & \text { Papaya } & 92.1 & 78.74 \\ 13 & \text { Vegetables } & 1547.617 & 1533.716\end{array}$

Fuzzy Logic provides an effective solution in a beautiful way for many problems. Since this provide the correct methodology for decision making with accurate results.

Say, for example the present system is simple deciding the farmer's category like a marginal farmer, small farmer, or other category i.e., the existing system always classifies based on the location, how many acres land they have, caste or religion where they belongs. But, in reality a person may have a land of 20 acres in his or her name but no water source for a number of years. Or the cost of water source may be high, that means bore cost or electricity cost, etc. Similarity labor and infrastructure cost may not be properly included. In some case yielding of the food grains may not calculated properly for that reason proper estimation methods used or not! These factors play a vital role, if not we need work on those attributes.

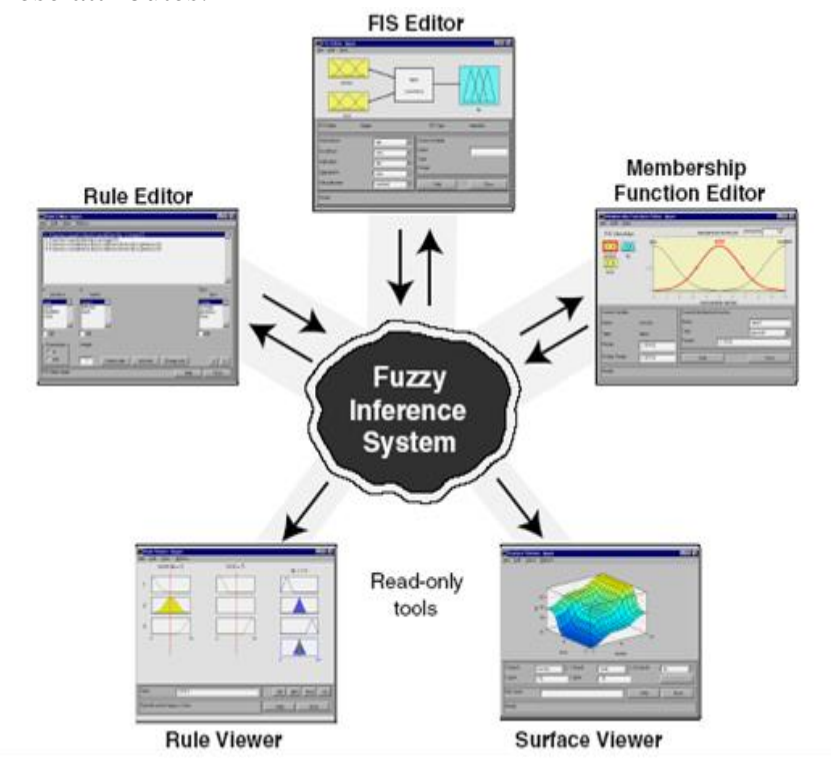

Fig. 8 FIS view

Hence, the proposed Fuzzy Based Intelligent System provides farmers to know the soil condition, type of the fertilizer, water usage / availability, optimizing these resources in a systematic way will provide the best solution.

\section{RESULT AND DISCUSSION}

The Weather forecasting situation and market strategies should be identified properly. Since the same commodity may available in the same location with a bulk. But, in another area the same may be a shortage. How to overcome this? What kind of business, strategies we need to follow? How can get maximum profit?

How we can minimize product cost? If we find the market somewhere else! What about the distance and mode of transportation along with shipment cost and damage of the product?

The FIS will discover these solutions in a better meaningful way with optimal time. 
Fuzzy Viewer:

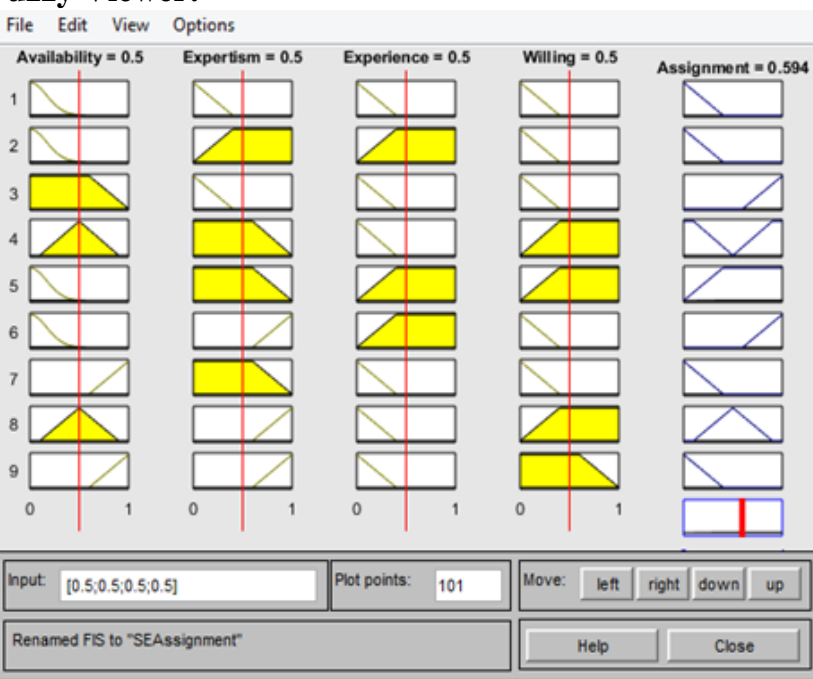

Fig. 8 Satisfaction of product quality as attributes

\section{Fuzzy Rule Editor:}

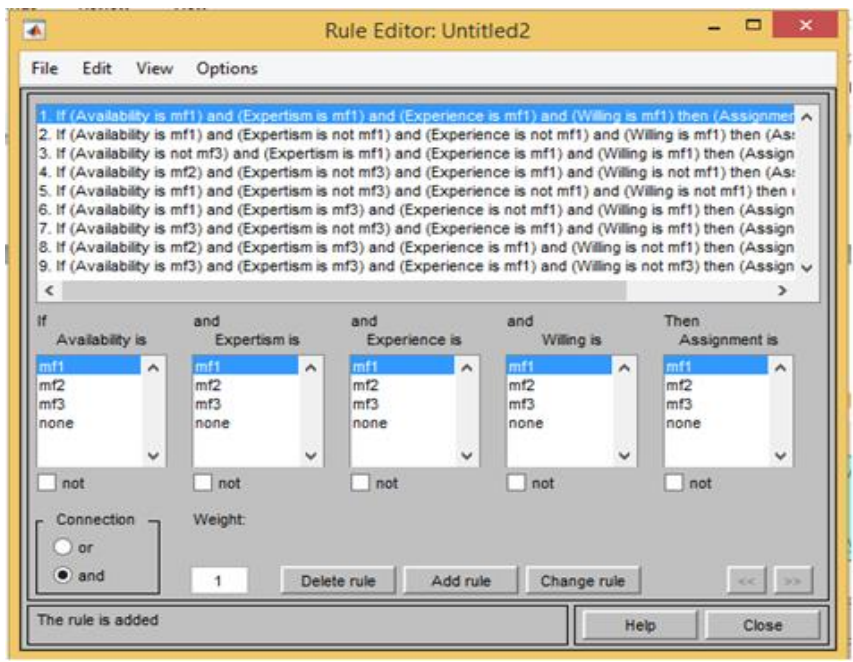

\section{Animal Husbandry \& Fisheries:}

Food is also obtained from animals for which animals are reared at home or in farms.

Sl No AnimalH No.of Livestock Lost qualifying

1 Buffalo/Cow 11461104

2 Buffalo/Cow with PTD 281042

3 Sheep/Goat 57785533

4 Bullock/He Buffalo 140110

5 Calf 262261

6 Backyard Poultry17311443

7 Broilers 4827348235

8 Layers 3831735085

9 Cattle Sheds 3690236618

10Poultry Sheds 353320

Fisheries like Fish, Prawn, Tank Fish, Sea Fish \& River side etc...

Sl No Fisheries Department Units

1 Partially Damaged of Boats7494833

2 Partially Damaged of Nets 7970769

3 Fully Damaged of Boats 11969420

4 Fully Damaged of Nets 23517781.1

5 Boats or Nets fully damaged 324

6 FISH/PRAWN ponds damaged 556821

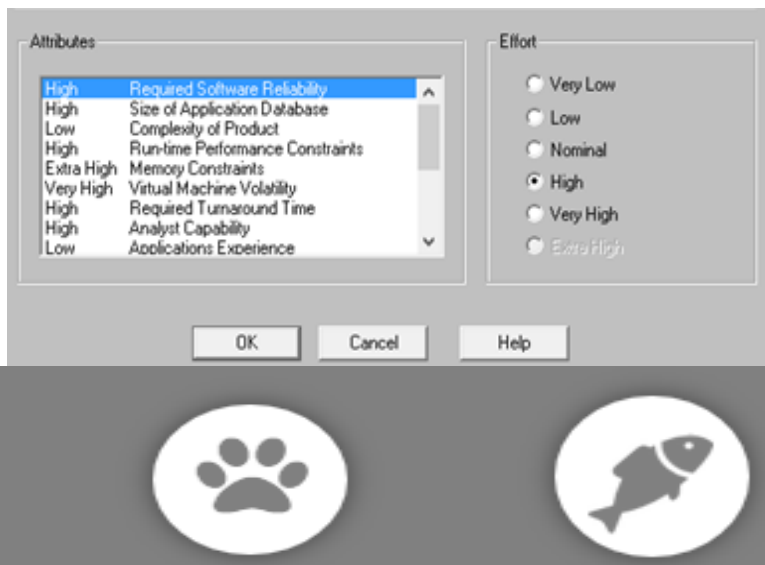

\section{ANIMAL HUSBANDRY FISHERIES}

Fig. 8 Satisfaction Metrics - Animal Husbandry \& Fisheries

The price fixing strategies for petrol, oil, gas, gold, and many more products completely produced by the corporate sector are different. As a common man when we are asking to person having complete knowledge why petrol price or gold price is rising or changing daily? They are saying something, but that in not true for all the well-developed countries. Why partiality on food grains? Probably no well-known corporate sector not involved in the agricultural sector!

Always there is a limit for budget with respect agricultural sector. Without knowing the ground reality few who are part of the system are fixed. This has to change.

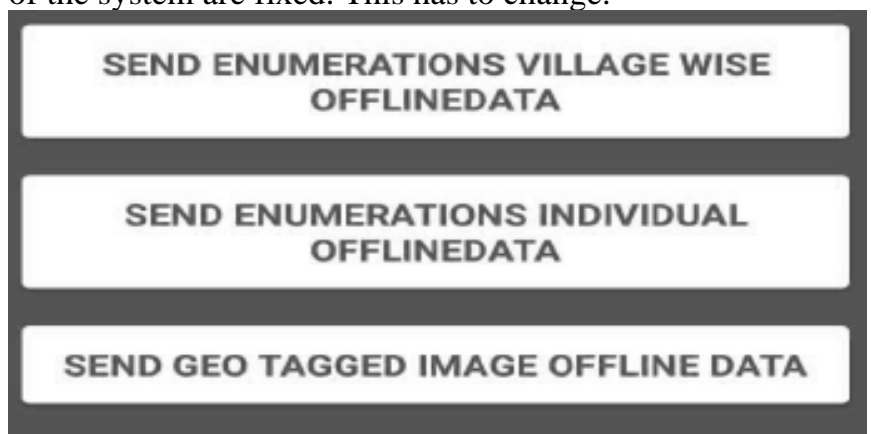

\begin{tabular}{|c|c|c|}
\hline 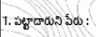 & 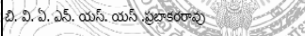 & 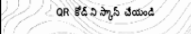 \\
\hline 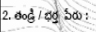 & त्यिसेव जय & \multirow{4}{*}{ 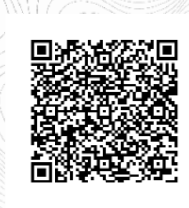 } \\
\hline 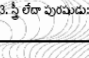 & 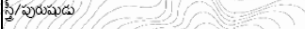 & \\
\hline 4.300 & 9441472602 & \\
\hline $5.060 \%$ 3.: & $x x x x x x x \times 5370$ & \\
\hline \multirow[t]{2}{*}{ 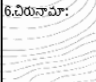 } & & \\
\hline & & 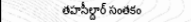 \\
\hline
\end{tabular}

MSPs on all the agricultural products be implemented by State or Central Governments. Of course not on paper, but in real!

How? To answer this we need to identify the person having agricultural land in acres with survey number must be linked with crop he or she cultivated in that season. How much quantity he or she cultivated what kind of support is required form the government sector should recorded by the enumerator through this FIS system [11-13].

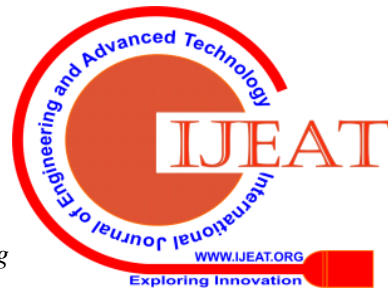


Sl No Agriculture Area Damaged (above 33\%)

1 Blackgram 3.273 .27

2 Cashew 8.24 8.24

3 Coconut 400.7

4 Cotton 4755.2564494 .471

5 Maize $18.67 \quad 18.67$

6 Mango 4.672 .67

7 Others 58.3347 .93

8 Paddy 196251.83555241574 .13275

9 Redgram 2.6022 .602

10Sugarcane $174.068 \quad 170.918$

11 Vegetales 0.330 .33

For example a person owns a costly car. Assume that there was an incident like theft, accident; own damage something, then what about an insurance claim. This is the situation in most of the countries with respect to car damage, but not to personal income, social status location where he or she belongs to. When claim settlement comes into reality a person having millions of dollars he or she may die then the amount will release to the nominee or not.

Now, the issue the same rule applicable to farmers with respect farming a particular food grain or not! What kind of mechanism we are following to recover the loss or damage for Animal husbandry \& Fisheries?. Whether we are doing the social/nation damage or not?

\begin{tabular}{|c|c|c|}
\hline $8 \%$ & $2555 \%$ & మండలం: \\
\hline 引́c & 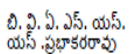 & 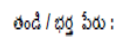 \\
\hline
\end{tabular}

\begin{tabular}{|c|c|c|c|}
\hline $\begin{array}{l}\text { వరుస } \\
\text { సంఖ్య }\end{array}$ & $\begin{array}{l}\text { సర్వే సెం. / సబ్ } \\
\text { డివిజసీ సెం. }\end{array}$ & 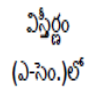 & 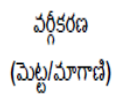 \\
\hline 1 & 8-29 & 0.0600 & సంజ \\
\hline 2 & 8-28 & 0.1200 & సంజ \\
\hline 3 & $6-8$ & 0.1600 & సంజ \\
\hline 4 & $6-41$ & 0.1200 & సంజ \\
\hline 5 & $62-3$ & 0.0300 & పుంజ \\
\hline 6 & $6-19$ & 0.0700 & నow \\
\hline 7 & $6-12$ & 0.0500 & నంబ \\
\hline 8 & $5-21$ & 0.0300 & సంజ \\
\hline 9 & $5-2$ & 0.2500 & సంజ \\
\hline 10 & $4-2$ & 0.2600 & నంజ \\
\hline
\end{tabular}

\begin{tabular}{|l|l|l|r|}
\hline \multicolumn{1}{|c|}{ సర్వే నెం. } & \multicolumn{1}{|c|}{ భూధార్ } & \multicolumn{1}{|c|}{ స్వభావం } & విస్తీర్ణం(ఎ.సెం) \\
\hline $103-9$ & 99.560 .667 .958 & పట్టా & 0.0400 \\
\hline $15-13$ & 99.723 .965 .235 & పట్టా & 0.0600 \\
\hline $15-4$ & 99.281 .034 .432 & పట్టా & 0.0700 \\
\hline $155-26$ & 99.424 .295 .713 & పట్టా & 0.0300 \\
\hline $155-40$ & 99.708 .065 .389 & పట్టా & 0.0300 \\
\hline $175-7$ & 99.921 .287 .889 & పట్టా & 0.0800 \\
\hline $18-23$ & 99.185 .422 .714 & పట్టా & 0.0800 \\
\hline $18-24$ & 99.676 .153 .840 & పట్టా & 0.0800 \\
\hline $18-26$ & 99.856 .317 .061 & పట్టా & 0.3100 \\
\hline $18-27$ & 99.291 .589 .408 & పట్టా & 0.1100 \\
\hline
\end{tabular}

Insurance: This scheme can be implemented in a better way with help of Budhar like Aadhar for a person Bhudhar for land which is being partly implanted in a few states so that we can easily track. The schemes were adopted as a pilot project in respect to paddy, wheat, etc., in many states. But real farmers were not benefitted due to some reason. When a natural calamity happened, at that particular situation there was no proper field visit with respect revenue records or survey numbers. Instead other party persons or political or fake people would get the benefit. Whatever it was certainly lose to the nation in many ways in general and lose to farmers in particular [14-16].

Code 9

\section{Beneficiary Name}

\section{Actual Cultivator}

Crop Name : $\quad$ Mango

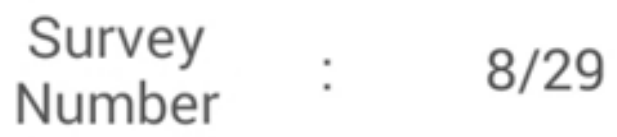

\section{Total}

damaged : $\quad .05$ area in acres 


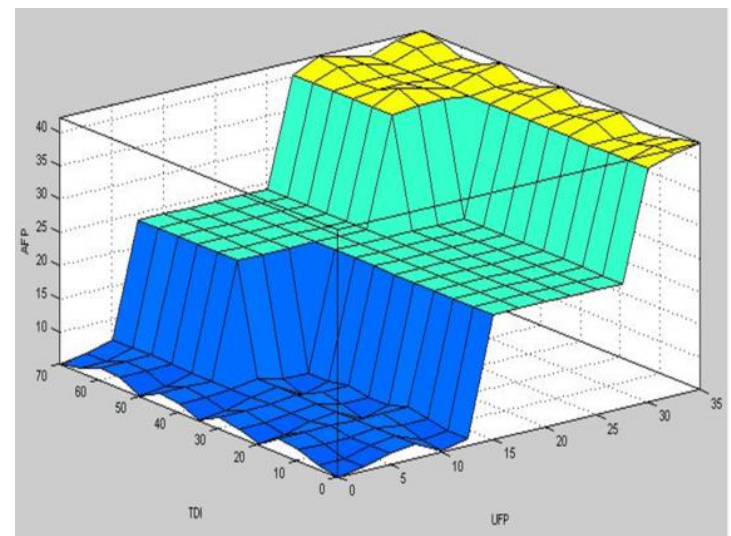

Fig. 9 Estimating Consumers Gain - Surface View

\section{CONCLUSION}

This research work concludes that any country' economic development is basically depends on the cultivation with respect to different food grains \& commodities. The main focus is to remove the role of middle man in each and every activity pertaining to the tasks carried by all the stakeholders of farming. With the help of the present proposal the gap between consumer and farmer reduced up to some extent. Finally, this work is based on gaining good returns for farmers by farmers meeting their own consumers, but no relation to dealers this helps in farmers getting their price for the work they do. In future we need to focus on this area, Not only that, but also how to get the minimum support price for the products at their door step in all the seasons. In the future, of course we need to supply different instruments with the help of technology to complete their tasks for planting, processing, and harvesting with an affordable price. Last but not least, many labors may not show interest to work in the field of agriculture so that the Government officials and NGOs must thin on this. Hence, the proposed intelligent system should suggest a better mechanism to eradicate this problem for smart cultivation.

\section{REFERENCES}

1. Johnston, B., and J. Mellor. "Rural Market Imperfections and the Farm Size-Productivity Relationship: Evidence from Pakistan." World Development 26 (10): 1807-26. 1961.

2. Heltberg, R. "Rural Growth Linkages: Household Expenditure Patterns in Malaysia and Nigeria." Research Report No. 41, International Food Policy Research Institute, Washington, D.C. 1998.

3. Haggblade, S., "Modeling Agricultural Growth Multipliers." American Journal of Agricultural Economics 73 (2): 361-74. ed. 2004.

4. Haggblade, S., Successes in African Agriculture: Building for the Future. Findings of an International Conference, Pretoria, South Africa, December 1-3, 2003. Feldafing, Germany: InWEnt. ed. 2004.

5. Hazell, P., Building on Successes in African Agriculture. 2020 Focus 12 (10 briefs). Washington, D.C.: International Food Policy Research Institute. 2005.

6. Rao, Jaggery Marketing Expert System Using Decision Tree, Sciences, Vol 1, Issue 1, Dec, 2010, Pp 17-24.

7. Rao, Design Of Tamarind Marketing Expert System Using Machine Learning Techniques; International Journal On Computer Engineering \& Information Technology, Issn 0974-2034, IJCEIT, December 2009 February 2010, Spring Edition 2010, Volume 22, Issue No 01, Pp. 29-38.

8. Rao, Diet Expert Advisory System, International Journal Of Computer Applications In Engineering, Technology And Sciences (IJ-CA-ETS), April '11 - Sept '11, Vol 3: Issue 2) Pp. 282-287;

9. Rao \& Ramaiah, Software Size Estimation Using Fuzzy Backpropagation Network Method; International Journal of Computer Science Issues(IJCSI), Vol. 9, Issue 1, No 1, 2012, Pp. 339-348. International Journal Of Advanced Computer And Mathematical

10. Rao \& Ramaiah, A novel approach to design Neuro-fuzzy expert system for software estimation, International Journal of Engineering Research \& Technology, Vol. 2 Issue 12, December - 2013, Pp.3012-3017.

11. Rao \& R Dhal, Service Cost Estimation in Cloud Environment Using a Third Party Web Server: A Comparative Analysis With and Without Using Cloud Computing, IOSR Journal of Computer Engineering, 1 (16), 72-77, 2014.

12. Rao \& Ramaiah, Organizational Strategies and Social Interaction Influence In Software Development Effort Estimation, Journal of Computer Engineering, Vol.16, Issue 2, Pp. 29-40, 2014.

13. Rao \& R Dhal, Shrinking The Uncertainty In Online Sales Prediction With Time Series Analysis, ICTACT Journal On Soft Computing Special Issue On Distributed Intelligent Systems And Applications, October 2014, Volume: 05, Issue: 01, Pp. 869-874.

14. Rao \& Ramaiah, Software Effort Estimation Framework To Improve Organization Productivity Using Emotion Recognition Of Software Engineers In Spontaneous Speech, ICTACT Journal On Soft Computing, October 2015, Volume: 06, Issue: 01, Pp:1076-1082.

15. Rao \& Ramaiah, A CASE Study on Software Project Development Cost, Schedule \& Effort Estimation, Asian Journal of Pharmaceutical and Clinical Research, Pp: 10-14, 2017.

16. Rao \& Ramaiah, Software Development Effort Estimation: A Framework, International Journal of Applied Business and Economic Research; Volume 15, Number 22, 2017, Pp.749-763.

\section{AUTHORS PROFILE}

Dr. B V A N S S Prabhakar Rao has obtained Bachelor of Science in

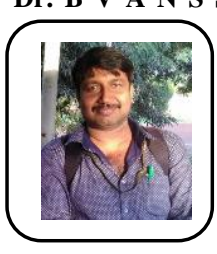
Electronics, Master of Computer Applications (MCA), M. Tech. Computer Science \& Technology from Andhra University, Visakhapatnam and Ph.D from Jawaharlal Nehru Technological University Kakinada. He published several papers in both national and inter-nation journals in the area of Software Engineering, Machine Learning, Soft Computing, Agriculture, Health Care, and Engineering Economics. He attended and presented several papers at both national and international conferences. He volunteered as reviewer for many books, international conferences \& journals. He is a Life Member in CSTA, IACSIT, IAENG, ISCA and ISTE.

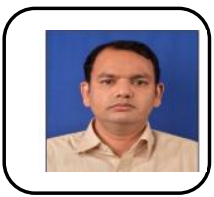

Dr. Kadupukotla Satish Kumar working as Associate Professor in Department of Computer Science at St. Peter's Engineering College. He publishes a good number of papers in national and international journals. His area of research is Safety Critical Systems \& Embedded Systems. Presently he is working on Microprocessors.

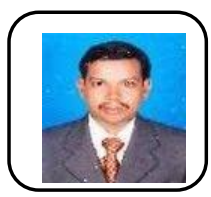

Prof. Rabindra Kumar Singh Working as Assistant Professor (Selection Grade ) in School of Computing Science and Engineering at zand Engineering from Anna University, Chennai in 2014. Currently pursuing Ph.D from Vellore Institute of Technology, Chennai Campus. He is interested in teaching the subject like Operating System, Computer Network, Data Mining, Software Project Management, Distributed Computing, Python Programming, R Tools, etc. His area of research is Machine Learning, Data Mining, and Bioinformatics etc..

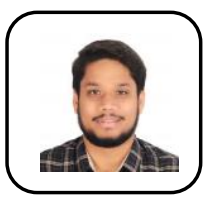

Mr. Pidugu Sundeep has completed his bachelor from VIT University in Computer Science and Engineering. His interest in working and contributing to Open Source projects and research, always helped him in gaining global practical exposure towards the latest technologies across varying platforms. He is currently working at Pagemajik Developing Deep Learning models for NLP and Image Processing projects. He is always passionate about bridging academic intellect towards practicalities in the industry. 